\title{
Nodal Marginal Zone Lymphoma by Ann Arbor Stage
}

National Cancer Institute

\section{Source}

National Cancer Institute. Nodal Marginal Zone Lymphoma by Ann Arbor Stage. NCI

Thesaurus. Code C141261.

An anatomic stage for nodal marginal zone lymphoma based on the Ann Arbor classification criteria. 